\title{
A Bean cDNA Expressed During a Hypersensitive Reaction Encodes a Putative Calcium-Binding Protein
}

\author{
J. L. Jakobek, J. A. Smith-Becker, and P. B. Lindgren \\ Department of Plant Pathology, North Carolina State University, Raleigh 27695-7616, U.S.A. \\ Accepted 27 April 1999.
}

\begin{abstract}
The hypersensitive reaction (HR) is an inducible plant response that is associated with disease resistance. It is characterized by rapid, localized cell death at the site of infection and is believed to inhibit the spread of invading pathogens. We have isolated a cDNA clone, designated Hra32 (for hypersensitive reaction associated), corresponding to an RNA transcript that accumulates in bean during an HR. The predicted protein product of the Hra32 cDNA is an approximately $17 \mathrm{kDa}$ protein of 161 amino acids, with four putative EF-hand calcium-binding domains. The temporal pattern of $\mathrm{Hra32}$ transcript accumulation correlated closely with the onset of the HR in bean after inoculation with incompatible Pseudomonas syringae pv. tabaci and pv. tomato and with tobacco necrosis virus. Hra32 transcript also accumulated in bean in response to compatible $\boldsymbol{P}$. syringae pv. phaseolicola and was correlated with necrotic cell death associated with disease lesion formation. A more transient pattern of Hra32 transcript accumulation occurred in bean in response to general stimuli that did not result in the HR or host cell death. These treatments included infiltration with a $P$. syringae pv. tabaci Hrp ${ }^{-}$mutant, $P$. syringae pv. tabaci cells treated with kanamycin, Escherichia coli, P. fluorescens, or glutathione, and in response to wounding. Thus, there was differential accumulation of the Hra32 transcript in response to specific stimuli resulting in the HR, compared with general stimuli that did not result in cell death. We hypothesize that the Hra32 product may be a component of the pathway that leads to hypersensitive cell death.
\end{abstract}

A common response of plants to incompatible plant pathogens is the hypersensitive reaction (HR) (Goodman and Novacky 1994). The HR is a rapid, localized death of plant tissue at the site of infection that is believed to limit the multiplication and spread of invading pathogens. Studies have shown that this response is an active process dependent upon de novo host RNA and protein synthesis (Keen et al. 1981; Yoshikawa et al. 1978). Recent reports indicate that the HR is a form of programmed cell death (Dangl et al.

Corresponding author: P. B. Lindgren; E-mail: pete_lindgren@ @ ncsu.edu

Current address of J. A. Smith-Becker: Department of Plant Pathology, University of California, Riverside 92521-0415, U.S.A.

Nucleotide and/or amino acid sequence data are to be found at the GenBank data base as accession number AF145386 (for Hra32).
1996; Gilchrist 1998; Heath 1998). Significantly, the HR may be a universal response of plants to incompatible fungi, bacteria, viruses, and nematodes (Kaplan and Keen 1980; Goodman and Novacky 1994).

Accompanying the HR are a complex array of coordinately expressed plant responses (Goodman and Novacky 1994; Hammond-Kosack and Jones 1996). These responses include production of phytoalexins, lytic enzymes, proteinases, pathogenesis-related proteins, and various plant cell wall components. Also occurring concurrently with the HR are dramatic changes in the production of active oxygen species, lipid peroxidation, net fluxes of cellular $\mathrm{H}^{+}, \mathrm{K}^{+}$, and $\mathrm{Ca}^{2+}$, phospholipid turnover, depolarization of the plant cell membrane potential, electrolyte leakage, and a decrease in relative water content of cells. Mechanistic analyses of the HR have been complicated due to the coordinate induction of these responses, and it has not been determined whether they specifically contribute to the HR.

A number of important characteristics differentiate the HR from other putative plant defense responses. The HR is only induced by pathogenic microorganisms, or specific products derived from these organisms. Such products include the Harpins produced by certain phytopathogenic bacteria (Wei et al. 1992; He et al. 1993), the syringolides produced by strains of Pseudomonas syringae (Yucel et al. 1994), the elicitins produced by strains of Phytophthora (Yu 1995), and racespecific, proteinaceous elicitors from Cladosporium fulvum (De Wit 1997) and Rhynchosporium secalis (Knogge 1996).

Other putative plant defense responses (e.g., phytoalexins, lytic enzymes, and the deposition of certain cell wall components) may be induced by general stimuli such as wounding, UV irradiation, and heavy metals (Bowles 1990; Dixon and Harrison 1990; Dixon and Lamb 1990). Induction of the HR requires living, metabolically active pathogens; nonpathogenic microorganisms and pathogens that have been killed by heat, UV irradiation, or antibiotics will not induce the HR (Klement 1982; Goodman and Novacky 1994). In contrast, phytoalexins and defense transcripts can be induced in plants by metabolically inactive pathogens and by nonpathogenic microorganisms (Jakobek and Lindgren 1993). Thus, while other plant defense responses are induced by many general stimuli, the HR can only be induced during specific plantpathogen interactions or by specific compounds derived from plant pathogens.

Previous studies have elucidated many of the physiological changes that occur in plants during an HR (Goodman and Novacky 1994), but very little is known about the mo- 
lecular basis of this response. For instance, it has not been determined whether hypersensitive cell death occurs as a result of the action of a single gene product or a multi-step metabolic pathway. Although the HR is considered to be an important component of plant defense, a causal relationship between the HR and disease resistance has not been established. In addition, it is not known whether a relationship exists between the cell death that occurs during the HR and the cell death associated with disease lesion formation during compatible interactions (Dangl et al. 1996). In order to better understand the molecular basis of the HR, we sought to isolate genes that encode products needed for the development of this response. Here we report the isolation of a cDNA corresponding to a transcript that accumulated in bean during the expression of the HR. We also include Northern (RNA) analyses demonstrating that this transcript accumulates differentially in bean in response to specific stimuli that result in cell death, compared with general stimuli that do not induce cell death.

\section{RESULTS}

\section{Isolation of a novel cDNA associated with the expression of an HR.}

We previously reported that the HR could be separated from many of the other coordinately expressed responses that are activated in bean during an incompatible response (Jakobek and Lindgren 1993). Transcripts for phenylalanine-ammonia lyase, chalcone synthase (CHS), chalcone isomerase, and chitinase (collectively referred to as defense transcripts) accumulated and phytoalexins were produced in bean in response to infiltration with incompatible $P$. syringae pv. tabaci, which elicits an HR. These same transcripts and phytoalexins also accumulated in bean in response to $P$. syringae pv. tabaci $\mathrm{Hrp}^{-}$mutants that do not elicit an HR. These experiments suggest that there are specific plant genes that are expressed in bean when an HR occurs in response to $P$. syringae pv. tabaci that are not expressed in response to $P$. syringae pv. tabaci $\mathrm{Hrp}^{-}$mutants. Our experimental strategy for the isolation of such genes was based upon this hypothesis.

A cDNA library was constructed in the vector LambdaZAPII specific to bean tissue undergoing an HR after infiltration with incompatible $P$. syringae pv. tabaci. This library was assayed with a combination of differential screening and coldplaque screening (Ausubel et al. 1990; Hodge et al. 1992). During this process, we identified a cDNA clone, designated Hra32 (for hypersensitive reaction associated), corresponding to a transcript that accumulated during the HR. Comparison of the Hra32 DNA sequence with the data bases of the National Center for Biotechnology Information and the BLAST algorithm (Altschul et al. 1990) revealed that the putative Hra32 protein shared homology with proteins containing EF-hand calcium-binding domains (see below).

\section{The Hra32 product contains putative EF-hand calcium-binding domains.}

A near full-length cDNA complementary to the Hra32 gene was isolated following the procedure described in the Materials and Methods. This cDNA, designated Hra32-11, was sequenced and found to be $780 \mathrm{bp}$, including 54 and $243 \mathrm{bp}$ of $5^{\prime}$ and 3' untranslated sequence, respectively. Northern analysis demonstrated that the corresponding transcript is approximately 800 bases (data not shown). The putative Hra32-11 open reading frame (ORF) is 483 nucleotides and potentially encodes an approximately $17 \mathrm{kDa}$ protein of 161 amino acids (Fig. 1A). The GenBank accession number for the Hra32 sequence is AF145386.

BLAST searches indicated that Hra32-11 shares no detectable sequence homology with other reported defense genes or proteins. However, as mentioned above, Hra32-11 contains putative EF-hand calcium-binding domains. Other proteins with EF-hand domains include calmodulin, troponin C, caltractin, myosin regulatory light chain, calcineurin $\mathrm{B}$, aequorin, and various calcium-dependent protein kinases (Celio et al. 1996). EF-hand domains consist of 29 amino acids arranged in a helix-loop-helix conformation that allows for the reversible binding of $\mathrm{Ca}^{2+}$ (Moncrief et al. 1990). The predicted Hra32 product contains four putative EF-hand domains that are separated by a spacing of 9 amino acids. The helix-loop-helix regions of the four putative Hra32 EF-hand domains are shown in Figure 1A and the four calcium-binding loops of these domains are compared with the consensus sequence for this region in Figure 1B. It should be mentioned that the sequence of EF-hand 4 diverges from the EF-hand consensus (i.e., leucine at position 12 of the calcium-binding loop) such that it may not actually bind $\mathrm{Ca}^{2+}$ (Moncrief et al. 1990).

Recently, Jang and co-workers isolated an Arabidopsis thaliana cDNA that has significant homology to Hra32-11 (Jang et al. 1998). This cDNA, designated AtCP1, corresponds to an $\mathrm{NaCl}$-inducible transcript. AtCP1 is predicted to encode a protein, consisting of 155 amino acids with three EFhand calcium-binding domains, with unknown function. Interestingly, this protein is $54.3 \%$ identical to the Hra32 product. The amino acid sequence alignment of the Hra32 product and AtCP1 is shown in Figure 2, demonstrating the relative positions of, and the relationships between, the EF-hand domains found in these proteins. These results suggest that the Hra32 product and AtCP1 may be related members of a unique family of EF-hand calcium-binding proteins.
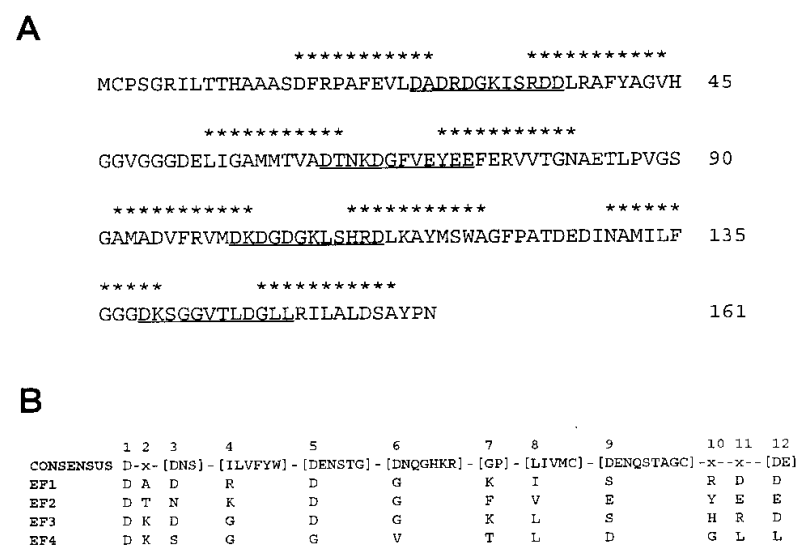

Fig. 1. A, Predicted product of the Hra32 open reading frame (ORF) showing the four putative EF-hand calcium-binding domains. Underlined amino acids constitute the EF-hand calcium-binding loops; amino acids with asterisks constitute the flanking $\alpha$-helixes. B, Comparison of amino acid sequences of the calcium-binding loop regions within the four EF-hands of the Hra32 ORF with the 12-amino-acid calciumbinding loop concensus sequence. 


\section{Analysis of Hra32 transcript accumulation during plant-pathogen interactions.}

Northern analysis was conducted with the Hra32 insert as a hybridization probe to determine the temporal relationship between Hra32 transcript accumulation and hypersensitive cell death. A visible HR occurs in bean between 10 and $12 \mathrm{~h}$ after infiltration with incompatible $P$. syringae strains. Hra32 transcript was detected in bean leaf tissue rapidly after infiltration with incompatible $P$. syringae pv. tabaci Pt11528, and detectable levels of Hra32 transcript remained high as the HR developed (Fig. 3). Incompatible P. syringae pv. tomato JL1065 also induces an HR on bean similar to $P$. syringae pv. tabaci Pt11528. Northern analysis was conducted to determine the temporal relationship between Hra32 transcript accumulation and the HR induced by P. syringae pv. tomato JL1065. The pattern of Hra32 transcript accumulation observed in bean after infiltration with incompatible $P$. syringae pv. tomato JL1065 was very similar to that observed after infiltration with $P$. syringae pv. tabaci Pt11528 (Fig. 4). Thus, Hra32 transcript accumulation in bean correlated with the production of the HR in response to both incompatible $P$. syringae pv. tabaci and pv. tomato.

CHS is induced during many incompatible plant-pathogen interactions resulting in an HR (Dixon and Lamb 1990), and was previously shown to be induced in bean in response to incompatible $P$. syringae pv. tabaci Pt11528 (Jakobek and Lindgren 1993). Therefore, the temporal pattern of Hra32 transcript accumulation in bean was compared with that of the CHS transcript after infiltration with this bacterium (Fig. 3). Similar to Hra32, CHS transcript accumulation was correlated with the production of the HR; however, CHS transcript accumulation was not as rapid as that detected with Hra32 transcript.

Bean plants were routinely infiltrated with water as a control treatment during the experiments described in this manuscript. In some experiments water infiltration induced a slight increase in Hra32 transcript accumulation (see Figure 3 for example). The levels of Hra32 transcript detected in such control plants were much lower than levels detected in plants infiltrated with other treatments. This response was not reproducible from experiment to experiment, and was due to an unknown stimulus.

The HR can be induced in plants in response to incompatible viruses, bacteria, fungi, and nematodes (Kaplan and Keen 1980; Goodman and Novacky 1994). Consequently, we were

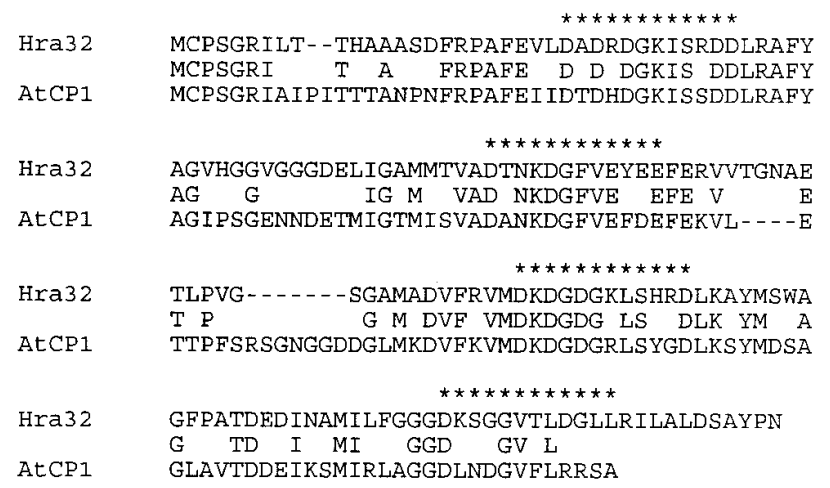

Fig. 2. Comparison of the predicted amino acid sequences of HRA32 and AtCP1. Sequence alignment was performed with the BLAST 2 Sequences program (National Center for Biotechnology Information). Calciumbinding loop region of the EF-hand domains is indicated by asterisks. interested in determining whether Hra32 transcript accumulated in response to another type of pathogen. Tobacco necrosis virus (TNV) induces necrotic local lesions on bean in response to mechanical inoculation. Local lesions are believed to be a form of the HR that inhibits incompatible viruses from spreading systemically through resistant plants (Fritig et al. 1987). Small, pin-point lesions began to be visible on bean leaves $24 \mathrm{~h}$ after inoculation with TNV; these lesions increased in number and in size to 2 to $3 \mathrm{~mm}$ in diameter by 96 $\mathrm{h}$ after inoculation. Northern analysis demonstrated that Hra32 transcript was detected in bean 48 to $72 \mathrm{~h}$ after inoculation with TNV (Fig. 5). In contrast, Hra32 transcript was not detected in uninoculated control plants (i.e., buffer-mock inoculated; data not shown). The time lag between the appearance of visible necrotic lesions and the appearance of the Hra32 transcript may have been due to the detection limits of our Northern protocol when the viral lesions were small. In conclusion, Hra32 transcript accumulated in bean during an incompatible viral interaction resulting in an HR.

Compatible disease interactions of plants and certain foliar bacterial pathogens (i.e., many strains of $P$. syringae) are characterized by plant tissue necrosis, or cell death, as a manifestation of symptom development. Inoculum concentrations of $10^{5}$ cells per $\mathrm{ml}$ are routinely used to study the development of disease symptoms during compatible interactions of plants and strains of $P$. syringae. When bean is infiltrated with compatible $P$. syringae pv. phaseolicola NPS3121 (causal agent of halo blight) at a concentration of $10^{5}$ cells per $\mathrm{ml}$, water-soaked disease lesions develop between 72 and $96 \mathrm{~h}$ after infiltration; as

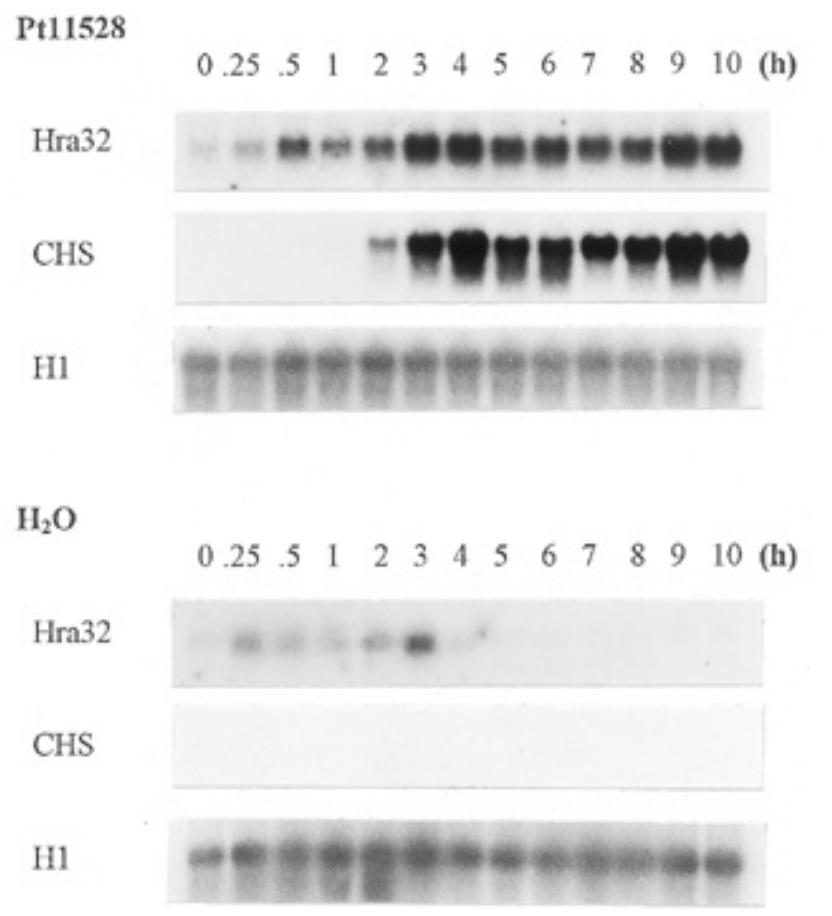

Fig. 3. Hra32 transcript accumulation in bean after infiltration with incompatible Pseudomonas syringae pv. tabaci Pt11528 (at a concentration of $10^{8}$ cells per ml). Total RNA was isolated at various times after infiltration and hybridized to ${ }^{32} \mathrm{P}$-labeled Hra32 or CHS. These blots were also hybridized with a bean cDNA clone, designated $\mathrm{H} 1$, that is complementary to a gene with an unknown function that is constitutively expressed (Lawton and Lamb 1987); this was used as a control to demonstrate equal RNA loading. 
these lesions increase in number and size, the infected tissue becomes necrotic and dies. When bean was infiltrated with NPS3121, with this inoculum concentration, Hra32 transcript accumulated in leaf tissue by $72 \mathrm{~h}$ after infiltration (data not shown). Thus, Hra32 transcript accumulated in bean leaf tissue as disease lesions developed during a compatible interaction.

Previous studies have demonstrated that, in addition to inducing disease symptoms at lower inoculum concentrations, various $P$. syringae strains can induce rapid cell death when introduced into compatible host plants at high inoculum concentrations (Klement 1982). These necrotic reactions are visibly indistinguishable from the HR induced by incompatible strains, except that the timing of the necrotic reactions in response to compatible strains is generally delayed, compared with incompatible strains (Klement 1982). For instance, a necrotic response is induced in bean 36 to $48 \mathrm{~h}$ after infiltration with $10^{8}$ cells per $\mathrm{ml}$ of compatible $P$. syringae pv. phaseolicola NPS3121. In contrast, the HR is induced in bean 10 to 12 h after infiltration with $10^{8}$ cells per $\mathrm{ml}$ of incompatible $P$. syringae pv. tabaci Pt11528. When we examined Hra32 transcript accumulation after infiltration with NPS3121 at a concentration of $10^{8}$ cells per ml, we found that Hra32 accumulated in bean by $10 \mathrm{~h}$ after infiltration (Fig. 6), which compares with $0.5 \mathrm{~h}$ after infiltration with Pt11528 (Fig. 3). Thus, Hra32 transcript accumulation was correlated with the development of tissue necrosis in bean in response to high inoculum levels of compatible $P$. syringae pv. phaseolicola.

\section{Analysis of Hra32 transcript accumulation \\ in response to the avirulence gene avrRpt2.}

The avirulence gene avrRpt2, from $P$. syringae pv. tomato JL1065, specifically interacts with the $A$. thaliana resistance gene RPS2 to elicit genotype-specific resistance and an HR (Kunkel et al. 1993; Yu et al. 1993). This $a v r$ gene also interacts in a similar manner with a resistance gene in bean (Innes et al. 1993). When bean cv. Red Kidney is infiltrated with $P$. syringae pv. phaseolicola NPS3121 containing avrRpt2, a rapid HR develops, and the normally compatible interaction is converted into an incompatible interaction. Consequently, we were interested in studying Hra32 transcript accumulation in response to avrRpt2. When bean was infiltrated with $P$. syringae pv. phaseolicola NPS3121 at a concentration of $10^{8}$ cells per $\mathrm{ml}$, Hra32 transcript accumulated $10 \mathrm{~h}$ and tissue necrosis developed 36 to $48 \mathrm{~h}$ after infiltration (Fig. 6). In contrast, when bean was infiltrated with NPS3121(avrRpt2) at the same concentration, Hra32 transcript accumulated at $4 \mathrm{~h}$ and an HR was induced approximately $12 \mathrm{~h}$ after infiltration (Fig. 6). Thus, in relation to Hra32 transcript accumulation and production of an HR, the response of bean to NPS3121(avrRpt2) was similar to that of $P$. syringae pv. tomato JL1065. Therefore, Hra32 transcript accumulation was correlated with HR tissue necrosis induced by the avirulence gene avrRpt 2 .

\section{Analysis of Hra32 transcript accumulation \\ in response to general stimuli.}

Previously, we demonstrated that defense transcripts accumulated and phytoalexins were produced in bean in response to general stimuli that do not elicit an HR or host cell death (Jakobek and Lindgren 1993). These stimuli included infiltration with heat-killed $P$. syringae pv. tabaci, $P$. syringae pv. tabaci treated with antibiotics that inhibit bacterial protein synthesis, $P$. syringae pv. tabaci $\mathrm{Hrp}^{-}$mutants, Escherichia coli, and $P$. fluorescens. Therefore, we wanted to determine whether the Hra32 transcript accumulated in response to general stimuli. When bean was infiltrated with the $P$. syringae pv. tabaci Hrp- mutant Pt11528::Hrp1 with an inoculum of $10^{8}$ cells per ml, Hra32 transcript accumulated even though an HR did not occur. Significantly, the temporal pattern of accumulation was distinct, compared with that of wild-type Pt11528 (Fig. 7). After infiltration with Pt11528::Hrp1, Hra32 transcript rapidly accumulated, but then decreased, and was not detected above background levels by $8 \mathrm{~h}$ after infiltration. Thus, Hra32 transcript accumulation occurred earlier and was much more transient in response to infiltration with Pt11528::Hrp1 than in response to infiltration with Pt11528.

CHS transcript previously was shown to accumulate in bean in response to infiltration with $P$. syringae pv. tabaci Pt11528::Hrp1 (see Jakobek and Lindgren 1993). Therefore, the temporal pattern of CHS transcript accumulation in bean was compared with that of Hra32 transcript after infiltration with this bacterium (Fig. 7). CHS transcript did not accumulate as rapidly as Hra32 transcript after infiltration with Pt11528::Hrp1. In addition, the CHS transcript was still detected $10 \mathrm{~h}$ after infiltration, whereas Hra32 was not (Fig. 7). Thus, the pattern of CHS accumulation was distinct from that observed for Hra32 transcript accumulation after infiltration with Pt11528::Hrp1.

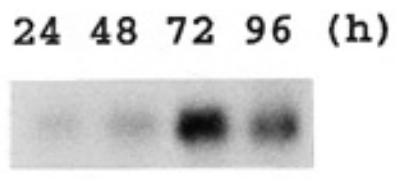

Fig. 5. Hra32 transcript accumulation in bean in response to tobacco necrosis virus (TNV). Total RNA was isolated at various times after mechanical inoculation with TNV and probed with the ${ }^{32} \mathrm{P}$-labeled Hra32 insert. Hra32 transcript was not detected in uninoculated control plants (data not shown).

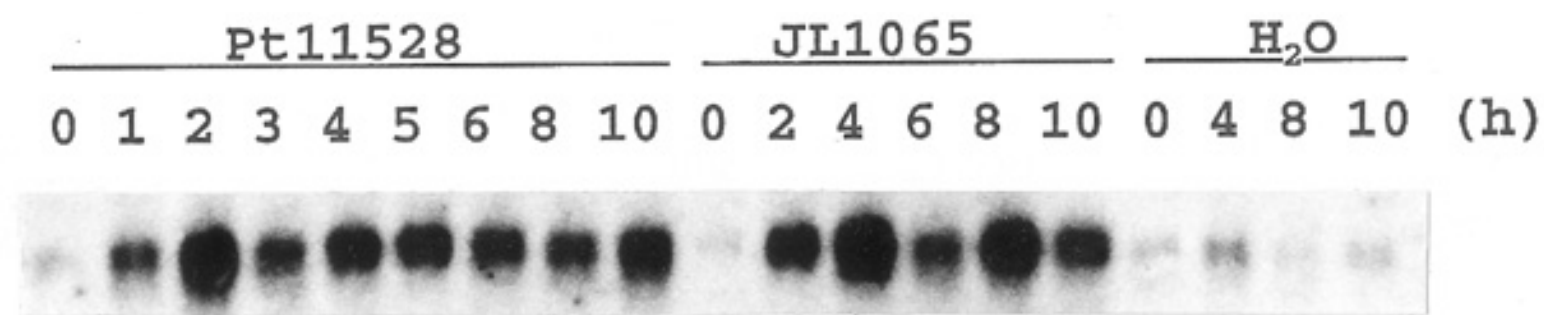

Fig. 4. Hra32 transcript accumulation in bean after infiltration with incompatible Pseudomonas syringae pv. tabaci Pt11528 or pv. tomato JL1065 (each at a concentration of $10^{8}$ cells per ml), or $\mathrm{H}_{2} \mathrm{O}$. Total RNA was isolated at various times after treatment and hybridized to ${ }^{32} \mathrm{P}-\mathrm{labeled} \mathrm{Hra} 32$ insert. 
We also examined the accumulation of Hra32 transcript in bean in response to other general stimuli that do not induce an HR or host cell death. The development of an HR is dependent upon de novo bacterial protein synthesis (Sasser 1978). When bean was infiltrated with $P$. syringae pv. tabaci Pt11528 cells treated with kanamycin, an inhibitor of bacterial protein synthesis, the HR was not induced. However, Hra32 transcript accumulation was very similar to that observed after infiltration with Pt11528::Hrp1, in that Hra32 transcript accumulated rapidly after infiltration but was not detectable above background levels by $10 \mathrm{~h}$ after infiltration (Fig. 8). This transient pattern of Hra32 transcript accumulation was also observed in bean in response to wounding (Fig. 9), or after infiltration with E. coli, P. fluorescens, or glutathione, none of which elicit an HR (data for the last three treatments not shown). Thus, a rapid and transient pattern of Hra32 accumulation was observed in bean in response to general stimuli that did not elicit an HR or host cell death.

\section{DISCUSSION}

The HR is a putative plant defense response that has been the focus of considerable research. Studies have elucidated many of the physiological and ultra-structural features associated with the HR; however, very little is known about the molecular basis of this response. Although believed to be an important component of disease resistance, the specific role of the HR as a defense mechanism has not been ascertained (Goodman and Novacky 1994). Significant progress has been made in identifying and cloning plant resistance genes and pathogen avirulence genes that presumably mediate the initial recognition events between the host and pathogen (Staskawicz et al. 1995; De Wit 1997). However, little is known about the downstream components of the signal transduction pathways involved with the activation of the HR after initial recognition events have occurred. Thus, additional studies of the HR are required to determine how this response specifically contributes to plant disease resistance, and how it is activated during plant-pathogen interactions.

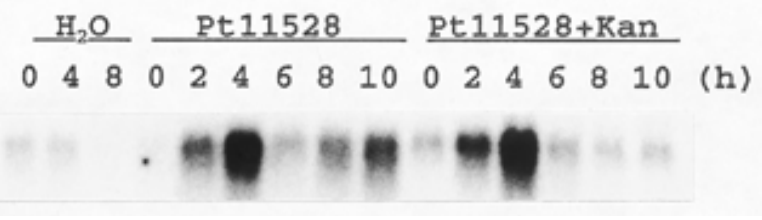

Fig. 8. Hra32 transcript accumulation in bean after infiltration with Pseudomonas syringae pv. tabaci Pt11528 or Pt11528 treated with kanamycin (labeled as Pt11528+Kan). Total RNA was isolated from bean at various times after infiltration and was hybridized to ${ }^{32} \mathrm{P}$-labeled Hra32.

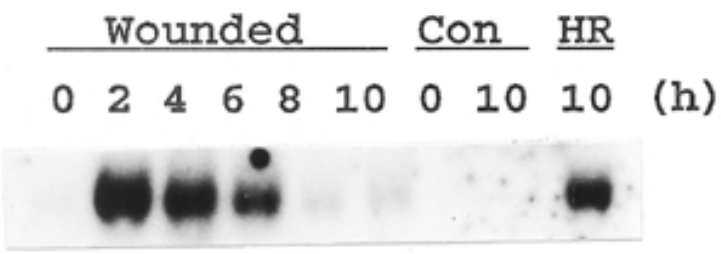

Fig. 9. Hra32 transcript accumulation in bean after wounding, or infiltration with $\mathrm{H}_{2} \mathrm{O}$ (labeled as Con) or Pt11528 (labeled as HR). Total RNA was isolated from bean at various times after treatment and was hybridized to ${ }^{32} \mathrm{P}$-labeled Hra32.

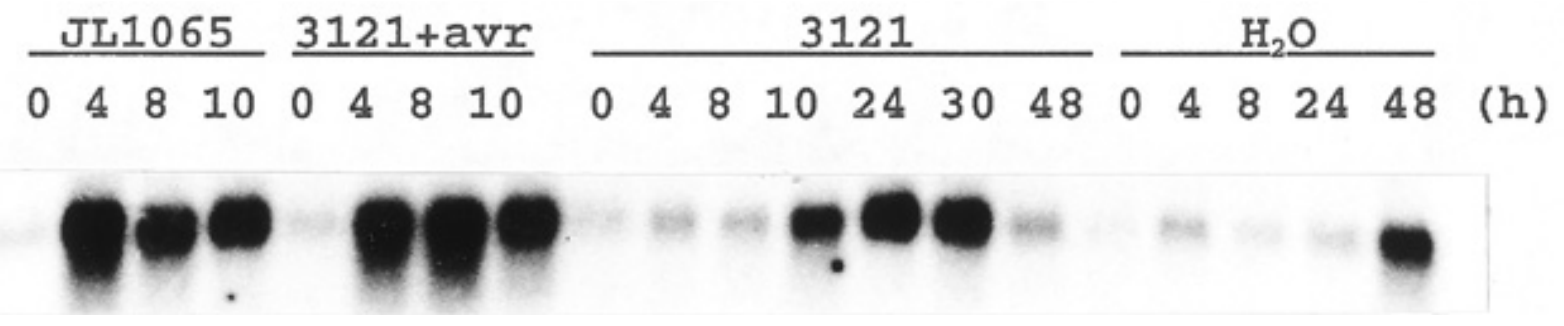

Fig. 6. Hra32 transcript accumulation during a gene-for-gene interaction. Total RNA was isolated from bean at various times after infiltration with $10^{8}$ cells per $\mathrm{ml}$ of Pseudomonas syringae pv. tomato JL1065, P. syringae pv. phaseolicola NPS3121 containing avrRpt2 (labeled as $3121+\mathrm{avr}$ ), wild-type NPS3121, or $\mathrm{H}_{2} \mathrm{O}$.

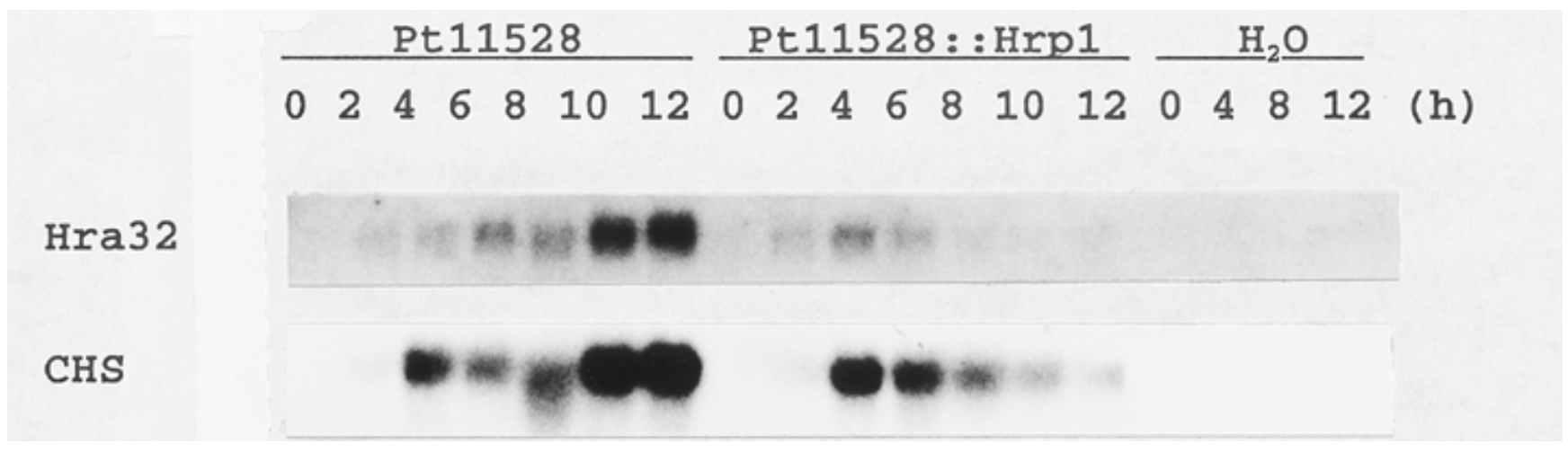

Fig. 7. Hra32 and chalcone synthase (CHS) transcript accumulation in bean in response to infiltration with an Hrp- mutant. RNA was isolated from bean at various times after infiltration with $10^{8}$ cells per ml of Pseudomonas syringae pv. tabaci Pt11528, Hrp- Pt11528::Hrp1, or $\mathrm{H}_{2} \mathrm{O}$. Total RNA was hybridized to ${ }^{32} \mathrm{P}$-labeled Hra32 or CHS. 
We have characterized a cDNA clone, designated Hra32, corresponding to a transcript that accumulates during the HR. A rapid and prolonged pattern of Hra32 transcript accumulation was observed in response to specific stimuli that elicit the HR, including $P$. syringae pv. tabaci, $P$. syringae pv. tomato, and TNV. In contrast, a rapid but transient pattern of Hra32 transcript accumulation was observed in response to general stimuli that do not elicit an HR, including infiltration with a $P$. syringae pv. tabaci $\mathrm{Hrp}^{-}$mutant, $P$. syringae pv. tabaci cells treated with kanamycin, E. coli, P. fluorescens, and glutathione, as well as in response to wounding. Thus, the pattern of Hra32 transcript accumulation observed during interactions when the HR occurred was different from that observed when the HR did not occur.

Our collective Northern data indicate that the Hra32 gene(s) may be regulated in at least two different manners, suggesting that there may be different regulatory elements involved with activating the Hra32 gene in response to specific stimuli that induce an HR versus general stimuli that do not induce an HR. Alternatively, Southern blot analysis suggests that Hra32 may be a member of a small gene family (data not shown); thus, different members of the Hra32 gene family may be induced by specific versus general stimuli. Recent studies have demonstrated that certain defense responses are activated by multiple, synergistic signals (Fauth et al. 1996; Graham and Graham 1996). Therefore, a third hypothesis to explain the different patterns of Hra32 transcript accumulation is that multiple, synergistic signals may activate the Hra32 gene once the HR has been initiated, leading to the prolonged pattern of Hra32 transcript accumulation. Multiple signals may not be induced by general stimuli, leading to the transient pattern of Hra32 accumulation. Additional studies are required to better understand the regulatory mechanism(s) associated with the activation of the Hra32 gene(s).

The fact that the Hra32 transcript accumulated during plantbacterial interactions that did not result in an HR does not preclude the hypothesis that the Hra32 product has an important role in the production of an HR. The product of nur77, a member of the steroid receptor superfamily, was shown to be essential for cell death in T cells (Liu et al. 1994). However, Northern analysis demonstrated that, like Hra32, nur77 transcript accumulated in T cells in response to specific treatments that induced cell death, as well as in response to general stimuli that activate cells but do not induce death (Liu et al. 1994; Woronicz et al. 1994). Significantly, Nur77 protein was present at high levels only in dying T cells (Woronicz et al. 1994). Thus, it is interesting to speculate that the Hra32 protein may be part of a pathway that leads to hypersensitive cell death.

Computer analyses demonstrated that the predicted product of the Hra32 gene contains four EF-hand calcium-binding domains, which suggests that it is a calcium-modulated protein. Calcium is required for the regulation of many processes in plants, including cell elongation, mitosis, polarized cell growth, cytoplasmic streaming, enzyme secretion, hormone action, turgor regulation, phototactic and gravitropic movements, and various enzyme activities (Heppler and Wayne 1985; Kauss 1987; Roberts and Harmon 1992). Calcium has also been implicated in the production of the HR, and is required for programmed cell death in animals (Goodman and Novacky 1994; Trump and Berezesky 1992).

Many of the proteins that contain EF-hand domains have important roles associated with regulation of cellular proc- esses (Moncrief et al. 1990; Celio et al. 1996). Three functions have been attributed to EF-hand calcium-binding proteins (Celio et al. 1996). Members of the first group interact with target proteins in a $\mathrm{Ca}^{2+}$-dependent manner to modulate protein activation. Proteins of the second group have direct $\mathrm{Ca}^{2+}$ dependent enzymatic activities. Members of the third group do not interact with other proteins but act as intracellular $\mathrm{Ca}^{2+}$ buffers, thereby modulating free cytosolic $\mathrm{Ca}^{2+}$ levels within cells. The role of the Hra32 protein during the HR is not known. The Hra32 protein is unlikely to be an enzyme because it lacks known domains consistent with an enzymatic activity. Therefore, the Hra32 protein may have a role in modulating the activity of other target proteins during the HR.

The Hra32 product is predicted to be $55 \%$ identical at the amino acid level to AtCP1, a protein from A. thaliana that is induced in response to salt stress (Jang et al. 1998). It remains to be determined whether the Hra32 protein and AtCP1 have similar functions in plants. Salt stress has been reported to induce nuclear degradation and DNA laddering in meristematic cells of barley roots, both of which are characteristic features of apoptosis, a type of programmed cell death (Katsuhara and Kawasaki 1996; Katsuhara 1997). Thus, salt stress may induce programmed cell death in some plants. Because of structural similarities, it is possible that the Hra32 protein and AtCP1 may represent a family of related proteins that have roles in the various forms of programmed cell death occurring in plants.

A common feature of symptom expression during compatible interactions is necrotic cell death associated with disease lesion formation (Dangl et al. 1996; Gilchrist 1998). Whether a relationship exists between this cell death and hypersensitive cell death is as yet unclear (Dangl et al. 1996; Gilchrist 1998). The fact that Hra32 transcript accumulated in bean as disease lesions formed in response to infection by compatible $P$. syringae pv. phaseolicola suggests that the Hra32 product may also have some role in the cell death associated with haloblight symptoms, as well as the HR.

In conclusion, we have isolated a cDNA, designated Hra32, corresponding to a transcript that accumulates during the HR. Hra32 transcript accumulation was also correlated with host cell death that occurred as a result of disease lesion formation. The predicted Hra32 protein shares significant homology to an A. thaliana protein that is induced by $\mathrm{NaCl}$ stress (Jang et al. 1998), and $\mathrm{NaCl}$ stress may induce apoptosis in certain plants (Katsuhara and Kawasaki 1996; Katsuhara 1997). Therefore, the Hra32 product may be involved in the production of the HR or, alternatively, it may be a component of multiple cell death programs. We are currently investigating the role of the Hra32 gene and gene product during plant-pathogen interactions.

\section{MATERIALS AND METHODS}

\section{Bacterial strains and growth conditions.}

The bacterial strains used in this study include $P$. syringae pv. tabaci Pt11528 (incompatible on bean; elicits HR; ATCC Type Strain), P. syringae pv. tabaci Pt11528::Hrp1 (Hrp- derivative of Pt11528; unable to elicit an HR on bean; Jakobek and Lindgren 1993), P. syringae pv. tomato JL1065 (incompatible on bean; elicits an HR; Whalen et al. 1991), P. syringae pv. phaseolicola NPS3121 (compatible on bean; incites halo blight; Lindgren et al. 1986), NPS3121 carrying the avirulence gene avrRpt2 on the plasmid pLH12 (incompatible on bean; elicits an HR; Innes et 
al. 1993), P. fluorescens Pf101 (saprophyte; unable to elicit an HR or incite disease on plants; Jakobek and Lindgren 1993), and $E$. coli $\mathrm{DH} 5 \alpha$ (unable to elicit an HR or incite disease on plants; Life Technologies, Grand Island, NY). Media and conditions used to culture bacterial strains were previously described (Jakobek and Lindgren 1993).

\section{Growth and inoculation of plants.}

Growth of Phaseolus vulgaris cv. Red Kidney and the procedures used to inoculate plants with bacterial strains were previously described (Jakobek and Lindgren, 1993). Bean leaves were mechanically inoculated with TNV following the procedure of Gooding and Kennedy (1985). Leaf tissue was mechanically wounded by crushing with forceps.

\section{Isolation of Hra32 cDNA clones.}

A cDNA library representing bean tissue undergoing an HR after infiltration with $P$. syringae pv. tabaci Pt11528 was generated in the vector $\lambda$ ZAPII with the ZAP-cDNA synthesis kit (Stratagene, La Jolla, CA) following the manufacturer's protocols. An HR is induced in bean within $12 \mathrm{~h}$ after infiltration with Pt11528 with an inoculum of approximately $10^{8}$ cells per $\mathrm{ml}$. Because the most biologically relevant time after infiltration for mRNA isolation in relation to the production of an HR was not known, poly $\left(\mathrm{A}^{+}\right) \mathrm{RNA}$ was isolated $0.5,3.0,5.5$, and $8.0 \mathrm{~h}$ after infiltration with this inoculum, pooled, and used to make the cDNA library. Plaque lifts were made with Colony/ Plaque Screen hybridization transfer membranes (NEN Du Pont, Boston, MA). The membranes were prehybridized and hybridized at $42^{\circ} \mathrm{C}$ in a solution consisting of $50 \%$ formamide, $5 \times$ Denhardt's solution $(1 \times$ Denhardt's solution is $0.02 \%$ Ficoll, $0.02 \%$ polyvinylpyrrolidone, $0.02 \%$ bovine serum albumin), $1 \%$ sodium dodecyl sulfate (SDS), $1 \mathrm{M} \mathrm{NaCl}$, $0.05 \mathrm{M}$ Tris- $\mathrm{HCl}(\mathrm{pH} 7.5)$, and $100 \mu \mathrm{g}$ of denatured salmon sperm DNA per $\mathrm{ml}$. The membranes were differentially screened with labeled cDNA complementary to pooled poly $\left(\mathrm{A}^{+}\right)$ mRNA isolated from bean leaf tissue $0.5,3.0,5.5$, and $8.0 \mathrm{~h}$ after infiltration with Pt11528 (the plus probe), and labeled cDNA complementary to pooled poly $\left(\mathrm{A}^{+}\right)$mRNA isolated from bean leaf tissue at comparable times after infiltration with $\mathrm{Hrp}^{-} P$. syringae pv. tabaci Pt11528::Hrp1 (the minus probe). Labeled cDNA for hybridization probes was generated following the protocol of the ZAP-cDNA synthesis kit, and added to the hybridization buffer at a final concentration of $10^{5} \mathrm{cpm} / \mathrm{ml}$. After overnight hybridization, the filters were washed in $2 \times \mathrm{SSC}$ ( $1 \times \mathrm{SSC}$ is $0.15 \mathrm{M} \mathrm{NaCl}, 0.015 \mathrm{M}$ sodium citrate, $\mathrm{pH} 7.0$ ) at room temperature for $5 \mathrm{~min}$, and then in $2 \times \mathrm{SSC}$ plus $1 \%$ SDS at $42^{\circ} \mathrm{C}$ for $30 \mathrm{~min}$. Filters were exposed to Kodak XAR5 film for various times at $-80^{\circ} \mathrm{C}$ with one Cronex Lightening Plus intensifying screen (NEN Du Pont).

In order to complete the cold-plaque screening, plaques that did not hybridize to the plus or minus probes were isolated by established techniques (Sambrook et al. 1989). DNA was isolated from these phage stocks as previously described (Hodge et al. 1992), and the resulting DNA served as templates for polymerase chain reaction (PCR) amplification of cDNA inserts. T7 and T3 RNA polymerase promoters flank the multiple cloning site of $\lambda$-ZAPII; therefore, the corresponding primers were used to prime PCR. PCRs were performed in $50-\mu \mathrm{l}$ volumes containing $10 \mu \mathrm{l}$ of phage DNA preparation, $200 \mu \mathrm{M}$ deoxynucleoside triphosphates, $0.5 \mu \mathrm{M}$ concentra- tions of each primer, $1.25 \mathrm{U}$ of Taq DNA polymerase (Promega, Madison, WI), $50 \mathrm{mM} \mathrm{KCl}, 10 \mathrm{mM}$ Tris- $\mathrm{HCl}(\mathrm{pH}$ 9.0), $0.1 \%$ Triton $\mathrm{X}-100$, and $2.5 \mathrm{mM} \mathrm{MgCl}_{2}$. Amplifications were performed in an MJR Programmable Thermal Controller model PTC-100 (MJ Research, Waterstown, MA) with 30 cycles of $1 \mathrm{~min}$ at $94^{\circ} \mathrm{C}, 1 \mathrm{~min}$ at $42^{\circ} \mathrm{C}$, and $2 \mathrm{~min}$ at $72^{\circ} \mathrm{C}$. Amplified DNA fragments were gel purified and labeled with $\alpha$ ${ }^{32} \mathrm{P}$-dCTP by random hexamer labeling (Feinberg and Vogelstein 1983). These labeled fragments were used as hybridization probes during diagnostic RNA slot blot analyses following previously described protocols (Jakobek and Lindgren 1993). This allowed for the identification of putative cDNA clones representing transcripts that were expressed during an HR.

The insert from the Hra32 cDNA was used as hybridization probe to identify Hra32-11, a full-length cDNA. The approximately 650-bp EcoRI-XhoI fragment from Hra32 was gel purified, random labeled with $\alpha-{ }^{32} \mathrm{P}-\mathrm{dCTP}$ and used to re-screen the cDNA library by the procedures described above. Positive clones from the first cycle of screening were purified by two additional rounds of screening.

\section{DNA sequencing and sequence analysis.}

The nucleotide sequence of the Hra32 and Hra32-11 inserts was determined with Sequenase vers. 2.0 T7 DNA polymerase (United States Biochemical, Cleveland, $\mathrm{OH}$ ). Synthetic oligonucleotides were synthesized as needed for primers, enabling sequencing of both strands of the Hra32 cDNAs. Homology searches were performed with the National Center for Biotechnology Information BLAST E-mail server (Altschul et al. 1990).

\section{RNA isolation and blot analysis.}

Total RNA was isolated from bean leaf tissue by the method of Wadsworth et al. (1988). RNA samples $(10 \mu \mathrm{g})$ were fractionated on a $1 \%$ agarose/formaldehyde gel in $1 \times 3-(\mathrm{N}-$ morpholino-)propanesulfonic acid (MOPS) buffer (Ausubel et al. 1990), and blotted to Genescreen Plus hybridization membrane (NEN Du Pont). Equal loading of samples was determined by including ethidium bromide in the sample allowing visualization of RNA by photography under UV light. The membranes were prehybridized and hybridized at $42^{\circ} \mathrm{C}$ in the hybridization buffer described above for library screening. Hybridization probes included the approximately 650-bp EcoRI-XhoI fragment from Hra32, the 780-bp EcoRI-XhoI fragment from Hra32-11, and the 1.4-kb EcoRI fragment from pCHS1 (cDNA clone for bean CHS; Ryder et al. 1984). Hra32 probes were double labeled with $\alpha-{ }^{32} \mathrm{P}$-dCTP and $\alpha-{ }^{32} \mathrm{P}$-dATP by random hexamer labeling, while CHS probes were labeled with $\alpha-{ }^{32} \mathrm{P}-\mathrm{dCTP}$ alone. Labeled probes were added to the hybridization buffers at final concentrations recommended by the manufacturer. The filters were hybridized for 16 to $18 \mathrm{~h}$, washed according to the manufacturer's directions, and exposed to X-ray film as described above.

\section{ACKNOWLEDGMENTS}

We thank Margo Daub and Marilyn Ehrenshaft for critical reviews of this manuscript, and Robert Kretsinger for helpful discussions about EFhand domains. We also thank J. B. Young for advice and help concerning TNV inoculations; Marvin Williams for photographic assistance; B. J. Staskawicz for pLH12: and O. W. Barnett for TNV. This work was partially supported by grants, nos. 89-37263-4737 and 91-37303-6432, from the United States Department of Agriculture. 


\section{LITERATURE CITED}

Altschul, S. F., Gish, W., Miller, W., Myers, E. W., and Lipman, D. J. 1990. Basic local alignment search tool. J. Mol. Biol. 215:403-410.

Ausubel, F. M., Brent, R., Kingston, R. E., Moore, D. D., Seidman, J. G., Smith, J. A., and Struhl, K., eds. 1990. Current Protocols in Molecular Biology. Wiley-Interscience, New York.

Bowles, D. J. 1990. Defense-related proteins in higher plants. Annu. Rev. Biochem. 59:873-907.

Celio, M. R., Pauls, T. L., and Schwaller, B. 1996. Introduction to EFhand calcium-binding proteins. Pages $15-20$ in: Guidebook to the Calcium-Binding Proteins. M. R. Celio, T. Pauls, and B. Schwaller, eds. Oxford University Press, Oxford.

Dangl, J. L., Dietrich, R. A., and Richberg, M. H. 1996. Death don't have no mercy: Cell death programs in plant-microbe interactions. Plant Cell 8:1793-1807.

De Wit, P. J. G. M. 1997. Pathogen avirulence and plant resistance: A key role for recognition. Trends Plant Sci. 2:452-458.

Dixon, R. A., and Harrison, M. J. 1990. Activation, structure and organization of genes involved in microbial defense in plants. Adv. Genet. 28:165-234.

Dixon, R. A., and Lamb, C. J. 1990. Molecular communication in interactions between plants and microbial pathogens. Annu. Rev. Plant Physiol. Plant Mol. Biol. 41:339-367.

Fauth, M., Merten, A., Hahn, M. G., Jeblick, W., and Kauss, H. 1996. Competence for elicitation of $\mathrm{H}_{2} \mathrm{O}_{2}$ in hypocotyls of cucumber is induced by breaching the cuticle and is enhanced by salicylic acid. Plant Physiol. 110:347-354.

Feinberg, A. P., and Vogelstein, B. 1983. A technique for radiolabeling DNA restriction endonuclease fragments to high specific activity. Anal. Biochem. 132:6-13.

Fritig, B., Kauffmann, S., Dumas, B., Geoffrey, P., Koop, M., and Legrand, M. 1987. Mechanism of the hypersensitivity reaction of plants. Pages 92-108 in: Plant Resistance to Viruses. B. N. Harrison, ed. John Wiley and Sons, New York.

Gilchrist, D. G. 1998. Programmed cell death in plant disease: The purpose and promise of cellular suicide. Annu. Rev. Phytopathol. 36:393-414.

Gooding, G. V., Jr., and Kennedy, G. G. 1985. Resistance in tobacco breeding line NC 744 to potato virus Y and inoculation by aphids. Plant Dis. 69:396-397.

Goodman, R. N., and Novacky, A. J. 1994. The Hypersensitive Reaction in Plants to Pathogens: A Resistance Phenomenon. American Phytopathological Society, St. Paul, MN.

Graham, T. L., and Graham, M. Y. 1996. Signaling in soybean phenylpropanoid responses - dissection of primary, secondary, and conditioning effects of light, wounding, and elicitor treatments. Plant Physiol. 110:1123-1133.

Hammond-Kosack, K. E., and Jones, J. D. G. 1996. Resistance genedependent plant defense responses. Plant Cell 8:1773-1791.

He, S. Y., Huang, H. C., and Collmer, A. 1993. Pseudomonas syringae pv. syringae harpin $\mathrm{Pss}_{\mathrm{P}}$ : A protein that is secreted via the Hrp pathway and elicits the hypersensitive response in plants. Cell 73:1255-1266.

Heath, M. C. 1998. Apoptosis, programmed cell death and the hypersensitive response. Eur. J. Plant Pathol. 104:117-124

Heppler, P. K., and Wayne, R. O. 1985. Calcium and plant development. Annu. Rev. Plant Physiol. 36:397-439.

Hodge, R., Paul, W., Draper, J., and Scott, R. 1992. Cold-plaque screening: A simple technique for the isolation of low abundance, differentially expressed transcripts from conventional cDNA libraries. Plant J. 2:257-260.

Innes, R. W., Bent, A. F., Kunkel, B. N., Bisgrove, S. R., and Staskawicz, B. J. 1993. Molecular analysis of avirulence gene avrRpt2 and identification of a putative regulatory sequence common to all known Pseudomonas syringae avirulence genes. J. Bacteriol. 175: 4859-4869.

Jakobek, J. L., and Lindgren, P. B. 1993. Generalized induction of defense responses in bean is not correlated with the induction of the hypersensitive reaction. Plant Cell 5:49-56.

Jang, H. J., Pih, K. T., Kang, S. G., Lim J. H., Jin, J. B., Piao, H. L., and Hwang, I. 1998. Molecular cloning of a novel $\mathrm{Ca}^{2+}$-binding protein that is induced by $\mathrm{NaCl}$ stress. Plant Mol. Biol. 37:839-847.

Kaplan, D. T., and Keen, N. T. 1980. Mechanisms conferring plant incompatibility to nematodes. Rev. Nematol. 3:123-134.

Katsuhara, M. 1997. Apoptosis-like cell death in barley roots under salt stress. Plant Cell Physiol. 38:1091-1093

Katsuhara, M., and Kawasaki, T. 1996. Salt stress induced nuclear and DNA degradation in meristematic cells of barley root. Plant Cell Physiol. 37:169-173.

Kauss, H. 1987. Some aspects of calcium-dependent regulation in plant metabolism. Annu. Rev. Plant Physiol. 38:47-72.

Keen, N. T., Ersek, T., Long, M., Bruegger, B., and Holiday, M. 1981. Inhibition of hypersensitive reaction of soybean leaves to incompatible Pseudomonas spp. by blasticidin S, streptomycin or elevated temperature. Physiol. Plant Pathol. 18:325-337.

Klement, Z. 1982. Hypersensitivity. Pages 149-177 in: Phytopathogenic Procaryotes. M. S. Mount and G. H. Lacy, eds. Academic Press, New York.

Knogge, W. 1996. Fungal infection of plants. Plant Cell 8:1711-1722.

Kunkel, B. N., Bent, A. F., Dahlbeck, D., Innes, R. W., and Staskawicz, B. J. 1993. RPS2, an Arabidopsis disease resistance locus specifying recognition of Pseudomonas syringae strains expressing the avirulence gene avrRPT2. Plant Cell 5:865-875.

Lawton, M. A., and Lamb, C. J. 1987. Transcriptional activation of plant defense genes by fungal elicitor, wounding and infection. Mol. Cell. Biol. 7:335-341.

Lindgren, P. B., Peet, R. C., and Panopoulos, N. J. 1986. A gene cluster of Pseudomonas syringae pv. phaseolicola controls pathogenicity on bean and hypersensitivity on non-host plants. J. Bacteriol. 168:512-522.

Liu, Z.-G., Smith, S. W., Mclaughlin, K. A., Schwartz, L. M., and Osborne, B. A. 1994. Apoptotic signals delivered through the T-cell receptor of a T-cell hybrid require the immediate-early gene nur77. Nature 367:281-284.

Moncrief, N. D., Kretsinger, R. H., and Goodman, M. 1990. Evolution of EF-hand calcium-modulated proteins. I. Relationships based on amino acid sequences. J. Mol. Evol. 30:522-562.

Roberts, D. M., and Harmon, A. C. 1992. Calcium-modulated proteins: targets of intracellular calcium signals in higher plants. Annu. Rev. Plant Physiol. Plant Mol. Biol. 43:375-414.

Ryder, T. B., Cramer, C. L., Bell, J. N., Robbins, M. P., Dixon, R. A., and Lamb, C. J. 1984. Elicitor rapidly induces chalcone synthase mRNA in Phaseolus vulgaris cells at the onset of the phytoalexin defense response. Proc. Natl. Acad. Sci. USA 81:5724-5728.

Sambrook, J., Fritsch, E. F., and Maniatis, T. A. 1989. Molecular Cloning: A Laboratory Manual. 2nd ed. Cold Spring Harbor Laboratory, Cold Spring Harbor, NY.

Sasser, M. 1978. Involvement of bacterial protein synthesis in induction of the hypersensitive reaction in tobacco. Phytopathology 68:361-363.

Staskawicz, B. J., Ausubel, F. M., Baker, B. J., Ellis, J. G., and Jones, J. D. G. 1995. Molecular genetics of plant disease resistance. Science 268:661-667.

Trump, B. F., and Berezesky, I. K. 1992. The role of cytosolic $\mathrm{Ca}^{2+}$ in cell injury, necrosis and apoptosis. Curr. Opin. Cell Biol. 4:227-232.

Wadsworth, G. J., Redinbaugh, M. G., and Scandalios, J. G. 1988. A procedure for the small-scale isolation of plant RNA suitable for RNA blot analysis. Anal. Biochem. 172:279-283.

Wei, Z.-M., Laby, R. J., Zumoff, C. H., Bauer, D. W., He, S. Y., Collmer, A., and Beer, S. V. 1992. Harpin, elicitor of the hypersensitive response produced by the plant pathogen Erwinia amylovora. Science 257:85-88.

Whalen, M. C., Innes, R. W., Bent, A. F., and Staskawicz, B. J. 1991. Identification of Pseudomonas syringae pathogens of Arabidopsis and a bacterial locus determining avirulence on both Arabidopsis and soybean. Plant Cell 3:49-59.

Woronicz, J. D., Calnan, B., Ngo, V., and Winoto, A. 1994. Requirement for the orphan steroid receptor Nur77 in apoptosis of T-cell hybridomas. Nature 367:277-281.

Yoshikawa, M., Yamauchi, K., and Masa, H. 1978. De novo messenger RNA and protein synthesis are required for phytoalexin-mediated disease resistance in soybean hypocotyls. Plant Physiol. 61:314-317.

Yu, G.-L., Katagiri, F., and Ausubel, F. M. 1993. Arabidopsis mutations at the RPS2 locus result in loss of resistance to Pseudomonas syringae strains expressing the avirulence gene avrRpt2. Mol. Plant-Microbe Interact. 6:434-443

Yu, L. M. 1995. Elicitins from Phytophthora and basic resistance in tobacco. Proc. Natl. Acad. Sci. USA 92:4088-4094.

Yucel, I., Midland, S. L., Sims, J. J., and Keen, N. T. 1994. Class I and class II $a v r D$ alleles direct the production of different products in gram-negative bacteria. Mol. Plant-Microbe Interact. 7:148-150. 